V.13, n.1: Ano: 2017.

\title{
RELATOS DE UMA MUHER NEGRA NA PÓS-GRADUAÇÃO: Trajetória educacional
}

\author{
Marcos Antonio Batista da Silva. Centro Universitário FIEO (UNIFIEO)/ Doutor em \\ Psicologia Social (PUC-SP) - marcos.psico@yahoo.com.br
}

\begin{abstract}
RESUMO: Este texto é um recorte de uma pesquisa que investigou trajetórias de estudantes negros da pós-graduação. Para este artigo privilegiamos discutir os relatos de uma mulher negra, titulada mestra no ensino superior/pós-graduação no Brasil, captados em entrevista individual semiestruturada e transcrita em forma de texto. A fim de se compreender trajetórias de estudantes negros do ensino superior/pós-graduação, faz-se necessário discutir à histórica condescendência das elites brasileiras com desigualdades sociais e ao racismo estrutural e simbólico contemporâneo. Encarar o debate sobre desigualdades educacionais e raciais historicamente acumuladas e socialmente reproduzidas no Brasil se apresenta, ainda, como um desafio de grandes proporções. Neste contexto perguntamos para a entrevistada sobre sua trajetória educacional até a pós-graduação. Indicamos que a trajetória educacional da entrevistada foi pautada de desigualdades sociais em razão de um racismo que integra as dimensões estrutural e simbólica na sociedade brasileira. Isto é, esse racismo atenta simultaneamente para as dimensões simbólica e estrutural na produção e sustentação de desigualdades sociais.
\end{abstract}

Palavras-chave: Desigualdade educacional. Pós-graduação. Muller negra.

\section{REPORTS OF A BLACK WOMAN IN GRAUATE STUDY:}

\section{Educational Trajectory}

\begin{abstract}
This article is part of a research that investigated trajectories of black graduate students. For this article, we prefer to discuss the reports of a black woman, titled master in higher education / postgraduate in Brazil, captured in a semi-structured individual interview and transcribed in text form. In order to understand the trajectories of black higher education / postgraduate students, it is necessary to discuss the historical condescension of Brazilian elites with social inequalities and contemporary structural and symbolic racism. Addressing the debate on historically accumulated and socially reproduced educational and racial inequalities in Brazil is still a major challenge. In this context, we ask the interviewee about her educational path to post-graduation. We indicate that the educational trajectory of the interviewee was based on social inequalities due to a racism that integrates the structural and symbolic dimensions in Brazilian society. That is, this racism is simultaneously attentive to the symbolic and structural dimensions in the production and sustainability of social inequalities.
\end{abstract}

Key-words: Educational inequality. Graduate study. Black woman.

\section{INTRODUÇÃO}


REVISTAELETRONICA

HinERARIUS

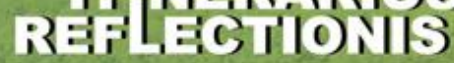

GRADUACSAO/PÓS.GRADUACSAO EM EDUCACAAO UFG/RE

V.13, n.1: Ano: 2017.

Para compreendermos as trajetórias de estudantes negros no ensino superior/pósgraduação não podemos deixar de mencionar sobre a presença reduzida de negros no ensino superior, que tem ocupado um espaço cada vez mais expressivo nas discussões das agendas de políticas públicas, dos movimentos sociais (Movimento Negro) e da academia. Assim, é necessário, por um lado, refletir sobre as desigualdades sociais que são atribuídas à herança do passado escravista, à política de branqueamento da passagem do século XIX para o XX, à histórica condescendência das elites brasileiras com desigualdades sociais e ao racismo estrutural e simbólico contemporâneo (GUIMARÃES, 2002; TELLES, 2003; ROSEMBERG et al, 2003). Por outro lado, atentar-se também nas modificações ocorridas no ensino superior na sociedade brasileira (política de ação afirmativa/ cotas, Enem).

Cinco produções podem ser utilizadas na construção desse quadro: o "Relatório Anual de Desigualdades Raciais no Brasil 2009-2010”, organizado por Paixão (2010) e produzido no Laboratório de Análises Econômicas, Históricas, Sociais e Estatísticas das Relações Raciais (LAESER); o artigo de Rosemberg; Madsen, publicado em 2011, na coletânea "O Progresso das mulheres no Brasil 2003 - 2010”, organizada pela Organização das Nações Unidas (ONU Mulheres); o estudo de Artes (2015) "Desigualdade de cor/raça e sexo entre pessoas que frequentam e titulados na pós-graduação brasileira: 2000 e 2010”. Relatório de Pesquisa Fundação Carlos Chagas S.P(FCC); o estudo de Artes et al. (2016) "Ações Afirmativas no Brasil: Experiências bem-sucedidas de acesso na pós-graduação” ,e "Ações Afirmativas no Brasil: reflexões e desafios para a pós-graduação" (ARTES et al.,2016).

Segundo Paixão (2010), o acesso de negros (pretos e pardos) ao ensino superior triplicou entre 1995 a 2006, porém, em 2006 os negros, na faixa etária dos 18 a 24 anos, representavam apenas $6 \%$ dos jovens nesse nível de escolarização. Resultado similar é apresentado por Rosemberg; Madsen (2011). Analisando dados da Pesquisa Nacional por Amostra de Domicílios (PNAD), 2003 e 2009, mostram que homens brancos e mulheres brancas, representavam 73,8\% dos/as estudantes universitários em 2003, e passaram a representar 42,3\% em 2009. Homens negros e mulheres negras representavam 25,1\% em 2003 e passaram a representar $35,1 \%$ em 2009.

Artes (2015) apresenta o comparativo entre os censos 2000 e 2010 para as pessoas que frequentam a graduação ou a pós-graduação e as taxas de variação no período, a partir de um conjunto selecionado de variáveis. 
REVISTA ELETRONICA

HWETARUS

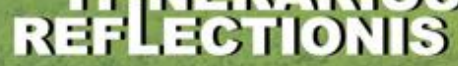

GRADUACAO/POS-GRADUACAO EM EDUCACAO

UFG/RE.

V.13, n.1: Ano: 2017.

Os resultados indicam um crescimento maior nas taxas de acesso à graduação $(116,4 \%)$ em comparação com as da pós-graduação $(57,1 \%)$. O aumento é mais acentuado na variável cor/raça, com índices que chegam a 290,7\% para os negros na graduação, mantendo a tendência na pós-graduação, com uma variação de 194,6\% de incremento entre 2000 e 2010 (ARTES, 2015, p.40).

Ou seja, se em uma primeira leitura a impressão pode ser de um maior equilíbrio no acesso ao ensino superior para os negros e brancos, a participação dos negros em relação a sua representação na população brasileira ainda mostra que as desigualdades são marca fundamental do ensino superior brasileiro. Artes (2015, p.40) assinala que "Em 2010 [...], os negros representavam 50,9\% da população geral, índice que diminui para 35,3\% nos grupo de graduandos e $24,9 \%$ de pós-graduandos.

No que tange as variáveis sexo e cor/raça, Artes (2015) observa que "são as mulheres negras que apresentam as maiores taxas de crescimento: $294,9 \%$ na graduação e $204,2 \%$ na pós-graduação" (ARTES, 2015,p.41). A autora também mostra os dados das pessoas graduadas e tituladas na pós-graduação por conjunto de variáveis selecionadas, Brasil 2000 e 2010 (IBGE, Censo Demográfico 2010 - microdados). Artes (2015) indica uma população maior de brancos na graduação $(79,2 \%)$ e na pós-graduação $(79,70 \%)$. No que se refere à população negra, o estudo mostra que na graduação há uma população de $25,0 \%$, e na pós-graduação $(18,1 \%)$. Isso implica que temos que avançar muito em termos de equidade na pós-graduação na sociedade brasileira.

No que se refere às produções de Artes et al.(2016), os estudos "são importantes ao contribuir para historiar o processo de democratização do acesso à Pós-graduação de grupos sub-representados, fazendo parte de um período de implementação exitosa de ações afirmativas na graduação" (ARTES et al.,2016,p.14). Desse modo, chamamos a atenção para as mudanças no perfil dos estudantes nos aspectos de pertencimento racial e origem social, entre outras. Tais mudanças devem ser avalizadas no contexto das políticas de ação afirmativa, que foram adotadas por governos no gerenciamento de suas políticas para o ensino superior na graduação, e que a partir da década de 2000, se estendeu também para a pós-graduação (ARTES, UNBEHAUM, SILVÉRIO, 2016).

Autores como Bourdieu (1999), Beltrão; Teixeira (2003); Artes (2015) assinalam que a presença negra na universidade, além de reduzida, é desigual e restrita a algumas áreas. Isto é, “[...] há uma clara separação das áreas por sexo: as mulheres concentram-se nas áreas de 
REVISTA ELETRONICA

HWERARUS

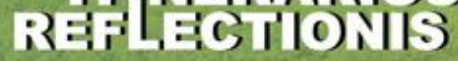

GRADUACAO/POS-GRADUAC AO EM EDUCACAO

UFG/REJ

V.13, n.1: Ano: 2017.

educação, humanidades e artes e saúde e bem-estar social, e os homens nas áreas de engenharia, produção e construção e agricultura e veterinária" (ARTES, 2015, p.52).

\section{PERSPECTIVA TEÓRICA}

Ao se inserir no universo dos estudos das relações raciais, e situar o assunto no campo da Psicologia Social no Brasil, é possível apreender que a temática das relações raciais integra há muito tempo o campo de estudos da Psicologia no Brasil (final do século XIX e início do XX), - Escola Nina Rodrigues. O período entre $(1930$ - 1950) foi marcado pela introdução da Psicologia na educação superior e pelo debate sobre a construção sociocultural das diferenças e da desconstrução do determinismo biológico de raças. No período da década de 1990, é retomada a discussão de maneira crítica sobre o legado social do "branqueamento" e de seus efeitos psicológicos sobre a identidade étnico/racial da população negra (SANTOS et al 2012).

No período entre (2000-2015) encontramos uma produção que dá ênfase a violência psicológica do preconceito e do racismo, ao monitoramento dos efeitos das políticas e dos programas de promoção da igualdade étnico-raciais (ações afirmativas, ensino da História e cultura afro-brasileira), bem como aos estudos sobre desigualdades de gênero, raça, idade e classe no contexto da educação brasileira.

Desse modo, ao ser proposta esta pesquisa, no campo da Psicologia Social no Brasil, é encontrado respaldo em Rosemberg (2001), quando esta esclarece que o papel da pesquisa na elaboração e avaliação de políticas públicas é instrumentalizar os atores sociais, especialmente os alijados de posições vantajosas, para participarem de negociações com o maior acervo de conhecimento possível.

Configura-se, assim, um compromisso ético e político: refletir sobre a produção e sustentação de desigualdades educacionais. Para a autora, e para nós, é necessário precisão no estudo das diferentes formas de desigualdade, pois as hierarquias de gênero, raça e idade se articulam de forma complexa, não sendo redutíveis umas às outras.

Este estudo se integra à linha de pesquisa “Aportes da Psicologia Social à compreensão de problemas sociais", que vem sendo desenvolvida pelo Programa de Estudos Pós-Graduados em Psicologia Social da PUC-SP junto ao Núcleo de Estudos de Gênero, Raça e Idade (NEGRI). 
REVISTA ELETRONICA

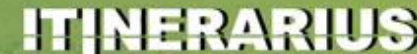

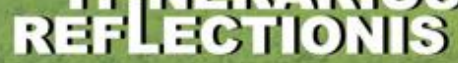

GRADUACSAO/POS-GRADUAC AO EM EDUCACAO UFG/RED

V.13, n.1: Ano: 2017.

O NEGRI foi coordenado pela professora Fúlvia Rosemberg, que, desde 1992, vinha orientando pesquisadores, negros e brancos, que focalizam, entre outros estudos, os das relações raciais, principalmente no contexto da educação brasileira. Adotamos para este estudo a perspectiva de Guimarães (2002), que considera o conceito analítico de raça como construção social é fundamental para a compreensão das desigualdades sociais, estruturais e simbólicas observadas sociedade em geral. As discriminações são subjetivamente justificadas ou inteligíveis apenas pela ideia de raça, a qual sustenta a discriminação e permite classificar e hierarquizar pessoas e segmentos sociais. Dessa maneira, o uso do conceito de raça no âmbito das ciências humanas e sociais ajuda a atribuir realidade social a certas discriminações e, por conseguinte, a lutar contra elas.

Aprofundando essa discussão, encontram-se autores como Essed (1991), Rosemberg et al (2003) e Guimarães (2005), que adotam uma concepção de racismo que integra as dimensões estruturais e simbólicas (ideológicas) na compreensão das desigualdades raciais. Segundo esses autores, no plano simbólico, o racismo manifesta-se na aceitação da crença da superioridade, entendida como natural, de um grupo racial sobre outro. No plano estrutural, os diferentes segmentos raciais têm, sistematicamente, acesso desigual a bens materiais e não materiais. Este estudo comunga com as reflexões desses autores sobre as desigualdades observadas entre negros e brancos no acesso a bens materiais e simbólicos, em razão do racismo constitutivo de nossa sociedade.

Rosemberg et al (2003) alertam ainda que, no plano simbólico, vive-se em uma sociedade que produz e sustenta uma ideologia da superioridade natural dos brancos sobre negros, pardos e indígenas. No plano material, grupos sub-representados ( negros, indígenas), não dispõem dos mesmos recursos públicos, ofertados por políticas públicas. Logo, considerase que o combate ao preconceito e ao estereótipo racial na educação, importante dimensão de combate ao racismo brasileiro em termos da produção acadêmica ou da ação dos movimentos sociais (Movimento Negro) pode ser a primeira etapa das estratégias de combate às desigualdades sociais no Brasil.

Dentro desse contexto, outra importante reflexão de Rosemberg; Madsen (2011) referem-se às desigualdades raciais e de gênero no sistema educacional. Para as autoras é necessária precisão para se estudar as diferentes formas de desigualdade, considerando as especificidades de cada identidade social, pois as hierarquias de gênero, raça, e idade se articulam de forma complexa, não sendo redutíveis umas às outras. 
V.13, n.1: Ano: 2017.

\section{MÉTODO}

Para esta pesquisa adotamos o método da hermenêutica de profundidade (HP) proposta de Thompson (2011), que propõe "o estudo da construção e contextualização social das formas simbólicas”(p.363). As formas simbólicas são aqui entendidas como ações, falas, imagens e textos recebidos, reproduzidos e colocados em circulação. No caso deste estudo, os discursos captados em entrevistas ${ }^{1}$ semi-estruturadas da entrevistada: mulher negra, com título de mestrado em Psicoloiga Social, que poderá auxiliar para a contextualizaçãoo das formas simbólicas em questão.

Thonpson (2011) compreende sua aplicação em três fases: análise sócio-histórica, análise formal ou discursiva e interpretação (ou reinterpretação). A primeira etapa do enfoque da hermenêutica de profundidade (HP) é a análise sócio - histórica, que tem por objetivo reconstruir as condições sociais e históricas de produção, circulação e recepção das formas simbólicas. A análise formal ou discursiva, segunda fase da HP, propõe o estudo das formas simbólicas que circulam nos campos sociais, ou seja, é a análise das características estruturais e das relações do discurso.

Conforme Thompson (2011), esta fase pode ser realizada por meio de diferentes tipos ou métodos de análise. Assim, adotamos também, a análise de conteúdo, seguindo as orientações Bardin (2011) e Rosemberg (1981) bem como, de recortes temáticos ajustados a cada tipo de discurso. A última etapa da HP, interpretação e reinterpretação, se constrói a partir das fases anteriores de análise sócio-histórica e análise formal ou discursiva.

A escolha do corpus teve como intuito, dar visibilidade a "pesquisadores negros" da pósgraduação sobre suas trajetórias educacionais. A titulação de mestre se justifica pela evolução do número de programa de mestrado e títulos concedidos no país.

O número de programas de mestrado continua crescendo a taxas significativas no Brasil. Em 1996, existiam 1.187 programas de mestrado no Brasil, enquanto que, no ano de 2014, o número desses programas já era de 3.620, como pode ser visto no Gráfico 1.1.01. Isso significa que houve um crescimento de $205 \%$ ao longo desses 19 anos. As taxas anuais de crescimento variaram, sempre positivamente, em média,

\footnotetext{
${ }^{1}$ A pesquisa seguiu a orientações da ética em pesquisa, de acordo com a Plataforma Brasil e do Comitê de ética da PUC-SP.
} 
REVISTAELETRONICA

HinERARIUS

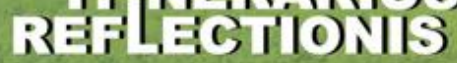

GRADUACAO/POS.GRADUACAO EM EDUCACAO

UFG/RES

V.13, n.1: Ano: 2017.

6,4\% nesse período. Mesmo tendo apresentado quedas ao longo dos três últimos anos da série, o nível mais baixo alcançado por essa taxa de crescimento, no ano de 2014, ainda foi relativamente elevado (4,3\%) (CGEE, 2015).

Vale ressaltar que a Extração de dados da base de Currículos Lattes em 31/01/2015 aponta 329.621 mestres cadastrados, sendo 74.360 no Estado de São Paulo. Mas sem informações disponíveis sobre a cor/raça dos pesquisadores brasileiros cadastrados. Embora os números sejam expressivos, o mesmo não se pode dizer com relação à categoria cor/raça.

Muito embora na pesquisa que originou este trabalho, tenhamos entrevistado quatro pessoas (mestres, autodeclarados negros, homens e mulheres), para este artigo privilegiamos os relatos de uma entrevista. Além disso, foi considerada sua trajetória educacional à luz das teorias das elações raciais de autores contemporâneos, bem como dos aportes teóricos sobre desigualdades educacionais no Brasil de autores contemporâneos (GUIMARÃES, 2002; ROSEMBERG et al.2003).

\section{RELATOS DE UMA PESQUISADORA NEGRA}

A primeira entrevistada ${ }^{2}$ tem mestrado em Psicologia Social por uma universidade particular do Estado de São Paulo. A entrevista iniciou-se no momento em que foi agendada e teve duração de aproximadamente 60 minutos. Procurou-se direcionar a conversa aos objetivos propostos da pesquisa, seguindo um roteiro semiestruturado. Permitiu-se que a entrevistada expusesse seus sentimentos, percepções e vivências. Para o pesquisador tratou-se de uma experiência intensa e importante pela motivação, emoção e participação da entrevistada, o que apontou que o pesquisador estava no rumo certo dos propósitos da entrevista.

No caso da entrevistada, pudemos notar boas afecções. Onde essas discussões buscam compreender a complexidade humana em um universo em que o entrevistado se encontra em relação constante com o outro a partir das experiências que vivencia. "Há, portanto, o homem por inteiro, de corpo e mente emoção e razão, determinado e determinante da sociedade, deforma que o que acontece com um afeta o outro" (SAWAIA,2009,p.365).

A mestra em Psicologia Social tem atuado principalmente com os seguintes temas de pesquisa: lutas culturais, narrativas audiovisuais, tradições de matrizes orais, identidade

\footnotetext{
${ }^{2}$ Denominamos a entrevistada como mestra em Psicologia Social.
} 
REVISTA ELETRONICA

HWERARUS

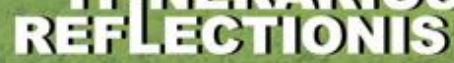

GRADUACSAO/POS-GRADUACAO EMIEDUCACAO UFG/RED

V.13, n.1: Ano: 2017.

afrodescendente no Brasil e na diáspora africana, cultura afro-brasileira e educação para as relações étnico-raciais. A fala da entrevistada correu límpida, sem titubeios. Nos olhos, a emoção, o brilho e alegria comuns dos que buscam em sua trajetória, um lugar existencial, um lugar hereditário que se completa por esse caminho de "pesquisadora negra". Mas quem vê a mestra em Psicologia Social, não faz ideia dos passos que precisou dar para chegar até a pósgraduação e se responsabilizar pelas exigências que recaem sobre uma mestra.

Ao ser perguntada se poderia falar sobre sua trajetória educacional até a universidade (mestrado), a entrevistada nos relata que no ensino médio fez escola técnica em instituição pública, curso de secretariado, para ter uma profissão e ingressar no mercado de trabalho. Fez estágios na área, porém, ela não se identificou com o curso, e percebeu que não teria felicidade nessa escolha. Neste contexto Rossler (2007) assinala que o ensino profissionalizante poderia ser uma solução para o problema de educação para o trabalho. Mas se faz necessário também, discutir a relação entre trabalho e o jovem. Isto é, analisar a questão da escolha profissional e da obtenção de um emprego e assim poder contribuir para a formulação de um projeto de vida adulta, crivado de valores sobre o sentido do trabalho como meio de realização pessoal e de participação na transformação do mundo.

A mestra em Psicologia Social em seus relatos traz à tona a fase da adolescência, o período em que o circular, ir e vir fora muito importante para ela. Assim, na fase da adolescência era próprio da entrevistada ansiar por oportunidades, formular projetos de vida adulta, deixarse fascinar pela liberdade, sonhar com experiências de realização no trabalho, nas amizades, na sociedade. Entendemos que não existe uma maneira única de ser adolescente. Cada um constrói, a sua maneira, um modo de ser, de agir, de confabular e de fazer sua história, dentro de uma circunstância dada. O sentido existencial do adolescente está em formação, o que o faz necessitar de coisas concretas e de sonhos. "A adolescência é vista como uma construção social com repercussões na subjetividade e no desenvolvimento do homem moderno e não como um período natural do desenvolvimento" (BOCK, 2007, p.68). A adolescência tem sido tema de interesse na sociedade e, consequentemente, a Psicologia tem dedicado a ela espaço importante, tanto no campo da Psicologia do Desenvolvimento quanto nas áreas de Psicologia da Educação e Psicologia Social.

A expectativa da entrevistada ao ingressar no ensino médio profissionalizante (secretariado) buscava uma profissão já de saída. Mas nem sempre a identificação com o curso 
V.13, n.1: Ano: 2017.

escolhido motiva os adolescentes. Desse modo, a mestra em Psicologia Social, após o término do ensino médio ingressa na universidade.

\begin{abstract}
Entrei para uma faculdade particular, mas que é uma fundação, então a mensalidade era bem abaixo do mercado e comecei a trabalhar na área de jornalismo, jornalismo cultural, que era a área em que eu me identificava mais, e no jornalismo cultural, a área de cultura negra realmente se fez a minha área de opção, mas como jornalista eu percebia que não iria sobreviver em uma área de cultura negra porque os veículos que aceitavam ou que tinham uma seção sobre o tema eram muito poucos (mestra em Psicologia Social).
\end{abstract}

Após o término da graduação, a entrevistada realizou uma especialização na área de jornalismo cultural, mas, "já sabendo" que queria trabalhar com cultura negra. Mas segundo ela, no jornalismo seria difícil. Nesta busca, a área de educação se abriu para ela. Assim a mestra em Psicologia Social ingressou no mercado de trabalho como educadora em um museu de temática africana e concluiu sua especialização, pesquisando cultura negra dentro do jornalismo.

Nota-se que historicamente, os temas de interesse da população negra não são assuntos recorrentes no jornalismo brasileiro. Temas como ações afirmativas, saúde da população negra, juventude negra, intolerância religiosa, entre outros, quando noticiados são frequente carregados de estereótipos, de ausência de imagens positivas e racismo (programas humorísticos, teledramaturgia), entre outros. Há setores que ainda fazem coberturas jornalísticas pouco consistentes sobre a temática negra, desfocadas da realidade e de forma sazonal. A ausência de jornalistas negros nas redações acentua o problema, e reflete as desigualdades sociais no Brasil. “[...] no Brasil, a mídia contribui para estigmatizar a população negra. Assim, a mídia constrói uma interpretação ideológica - na concepção de Thompson (2001) -, reproduzindo as relações de dominação sobre os negros pelo grupo dominante, os brancos"(ACEVEDO et al.2010,p.69).

A mestra em Psicologia Social, em sua trajetória não esmoreceu, foi à luta na busca por uma legitimação de seus propósitos, em particular, com as questões das relações raciais na sociedade brasileira. Trabalhando no museu, a entrevistada, ingressou na Pós-graduação (mestrado em Psicologia Social). Realizou o mestrado, para o qual não consegui bolsa e fez dívidas. O salário do seu emprego não permitia pagar o seu curso em uma universidade particular em sua totalidade. Para se manter em uma universidade particular no mestrado e 


\section{V.13, n.1: Ano: 2017}

custear suas despesas educacionais e pessoais a entrevistada fazia palestras aqui e acolá para ganhar outro pró-labore.

Segundo o estudo de Artes (2015) identificamos que 51,9\% dos estudantes do mestrado estudam e instituições de ensino superior pública e 48,1\% em instituições de ensino particular. No que se refere ao doutorado, encontramos uma população de $70, \%$ dos alunos em instituições de ensino públicas e 30\% em instituição de ensino particular. Quando consideramos recorte racial encontramos uma população de $54,8 \%$ de estudantes negros no mestrado em universidades públicas e 69,1\% nos cursos de doutorado. Ainda temos um grande desafio na pós-graduação que é tornar mais justa à distribuição de saberes no Brasil.

Na sequência desta sua luta diária, a entrevistada iniciou uma nova fase, isto é, trabalhar em projetos de intercâmbio cultural. Assim, a mestra em Psicologia Social foi para o exterior, e a ideia de trabalhar com África e Diáspora se abriu para ela. Um pouco deste percurso levou a entrevistada ao doutorado no curso que frequenta atualmente (História), na mesma universidade particular que concluiu o mestrado.

$\mathrm{Na}$ entrevista, perguntei a participante se ela poderia falar um pouco mais sobre sua trajetória educacional, considerando o relacionamento com os professores, colegas, e desempenho escolar.

Faz todo sentido que eu te diga que eu estudei em escola pública, até o que era naquela época a sexta série do ensino fundamental. Então quando eu tinha onze anos de idade, por escolha do meu pai, e pelas condições socioeconômicas que ele foi adquirindo, ele quis me transferir para uma escola particular. Essa transição foi muito difícil para mim, a sensação de não identificação, de ser colocada em um lugar e um ambiente em que eu não tinha a menor afinidade, tanto pela classe econômica dos estudantes da escola particular, como por causa da cor (mestra em Psicologia Social).

Eu lembro de que, se na escola estadual onde eu estudei, pessoas da minha cor eram maioria, e aí eu me refiro a cor parda, e pessoas de pele preta eram poucas, mas existiam e eram meus amigos, eu convivia e me sentia em casa[...] E chegar em uma escola em que isso praticamente não existia e as pessoas tinham um padrão de vida que não era o meu. As crianças e adolescentes chegavam com os seus tênis importados, e naquela época os aparelhos eletrônicos que eram walkmans ou coisa do tipo, e aquilo não era a minha realidade (mestra em Psicologia Social).

Meu pai se esforçou para pagar uma escola, mas a gente tinha uma condição justa para viver comedidamente e estudar em uma escola que fosse melhor. Então esse contexto era muito difícil de sociabilidade, e eu me pautava muito nas disciplinas que eu gostava e nas relações que eu estabelecia com os professores das disciplinas que eu gostava, sempre gostei de Língua Portuguesa e Inglês, pensando nas disciplinas da sétima série. Esses eram os professores com quem eu falava mais, trocava mais, e redações que eu escrevia e que acabavam trazendo um pouco da minha história e das minhas reflexões tocavam esses professores, eles percebiam que eu tinha certa inquietação, uma visão crítica que eu já desenvolvia naquela série, naquela faixa 
REVISTA ELETRONICA

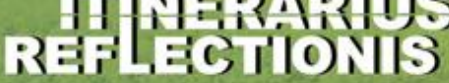

GRADUACGAO/POS-GRADUAC AO EM EDUCACAO

UFG/REJ

V.13, n.1: Ano: 2017.

etária, e era um pouco assim, com aqueles professores eu me dedicava e me relacionava bem, com outros não (mestra em Psicologia Social).

Para Martins e Geraldo (2013):

Observamos que se para a criança branca e pobre no processo de escolarização já há obstáculos na assimilação da cultura das classes dominantes exigidas pela escola, haja vista para as crianças negras, que são duplamente prejudicadas, pois além de pertencerem a camadas mais pobres da população e passarem por toda a sorte de adversidades, possuem características étnico-raciais, que fazem com que sejam estigmatizadas (p.59).

Neste contexto são imprescindíveis às contribuições dos movimentos sociais (Movimento negro) na luta dos negros na perspectiva de combate ao racismo estrutural e simbólico, seja no sistema educacional, no mercado de trabalho, bem como no sistema, politico, social e cultural.

Nota-se por um lado, as mudanças introduzidas nas condições de vida da população negra no Brasil verificada nos últimos anos como aponta informações do relatório do Instituto de Pesquisa Econômica Aplicada (IPEA, 2014) que são resultado do efeito combinado de iniciativas governamentais que sustentam a política de promoção da igualdade racial e sociedade civil, a partir de: políticas socioeconômicas gerais que impulsionam a inclusão da população negra; de ações para o atendimento a direitos básicos da população negra, por meio da incorporação da perspectiva racial na execução de políticas setoriais, como previsto no Programa Brasil Quilombola e no Plano Nacional de Desenvolvimento Sustentável dos Povos e Comunidades Tradicionais de Matriz Africana, além de programas de ação afirmativa para a promoção da igualdade de oportunidades, como é o caso do estabelecimento de cotas no acesso ao ensino superior público e no Programa Universidade para Todos (Prouni), voltado para instituições privadas.

Por outro lado, como assinalam Artes, Unbehaum e Silvério (2016):

A sociedade brasileira vivencia em 2016 um contexto político complexo, de incertezas, frente a um processo de Impeachment presidencial e um governo interino de perfil conservador. Essa realidade já se anunciava em 2015 com o enfraquecimento dos ministérios ligados à defesa de direitos humanos. [...]. Em 2016, a reforma administrativa, realizada pelo governo interino de Michel Temer, extinguiu o Ministério das Mulheres, da Igualdade Racial, da Juventude e dos Direitos Humanos, retornando à condição de Secretarias vinculadas ao Ministério da Justiça e Cidadania (p.14). 


\section{V.13, n.1: Ano: 2017.}

Na sociedade contemporânea e diante da desigualdade educacionais de grupos subrepresentados, é cada vez mais necessário, que os integrantes do sistema de ensino (educação básica, educação superior/pós-graduação) dialoguem e valorizem os marcos culturais formadores da sociedade brasileira, bem como o poder político, dialogue cada vez mais com os movimentos sociais. Sem isso, poderá estar comprometida a própria qualidade da educação democrática. Visto que, apesar do avanço nas condições de inserção econômica, educacional e social, da população negra na sociedade brasileira, ainda persistem grandes diferenciais que colocam os negros em desvantagem, comparativamente aos brancos, como vem sendo demonstrado por movimentos sociais brasileiros (Movimento Negro), bem como de outras Organizações e Institutos de pesquisas (IPEA, 2014).

Consideramos a expressão de preconceito interpessoal como apenas uma das manifestações do racismo brasileiro. Ou seja, para nós, o racismo brasileiro não se confunde com preconceito. Portanto, combater o "discurso racista", o racismo, não significa lutar contra indivíduos, mas se opor às práticas e ideologias pelas quais o racismo opera através das relações culturais e sociais. No plano simbólico, o racismo opera por expressão aberta de preconceito racial, considerando os negros como inferiores aos brancos. Esse plano do racismo é devastador, mas é insuficiente, por si só, para explicar toda a desigualdade racial brasileira. No plano material, negros não têm acesso aos mesmos recursos públicos que os brancos, inclusive aqueles destinados para as políticas públicas.

Outro relato importante da entrevistada se refere ao fato de estudar em uma escola católica:

\footnotetext{
O fato de ir para escola católica foi terrível para mim, minha família é católica, mas eu só fiz até a catequese e já tinha deixado essa questão de ir à missa quando eu fui para essa escola, então eu não me identificava com a doutrina religiosa na escola [...], eu não me identificava (mestra em Psicologia Social).
}

Esse relato está próximo de (CURY, 2004, p.184), quando o autor sublinha que o ensino religioso nas escolas apresenta um caráter problemático, porque "envolve necessário distanciamento do Estado laico ante o particularismo próprio dos credos religiosos". Compartilhamos com a reflexão do autor, quando esse assinala que cada vez que a religião é posta em cena dos projetos educacionais, sempre vem carregada de uma discussão intensa em torno de sua presença.

Esta discussão nos remete a outro contexto, que em linhas gerais, faz conexão com o relato da entrevistada: a implementação da Lei 10.639/03, alterada pela Lei 11.645/08, que 
REVISTA ELETRONICA

HWERARUS

Rहंदुनिता०

GRADUACAO/POS.GRADUACAO EM EDUCACAO

UFG/RED

V.13, n.1: Ano: 2017.

tornou obrigatório o ensino da história e cultura afro-brasileira e africana em todas as escolas, públicas e particulares, do ensino fundamental até o ensino médio. Entendemos que as leis, bem como suas práticas, constituem elementos significativos de estudos da realidade social, política e educacional. Elas refletem a tensão presente na história das políticas educacionais do país, Isto é, se de um lado há políticas que visam à permanência do racismo estrutural que se revela pela invisibilidade da raça e pelo mito da democracia e, de outro, há políticas frutos de lutas sociais que rompem com as primeiras (RIBEIRO, 2011).

Segundo Barros (2012, p.62), não é recente “'a preocupação com a elaboração de ações afirmativas para uma inserção do negro na sociedade, mas a criança negra na escola ainda cresce carente de identidade cultural', Ou seja, marcada pela descaracterização de seus valores e por um discurso de inferioridade. Barros (2012) discutiu em seu estudo, uma experiência de narração de mitologias de orixás na educação infantil. Esse estudo reflete como, por meio de elementos lúdicos, é possível trabalhar conteúdos necessários para uma política de inclusão desde o início da infância. Para Barros (2012), a experiência demonstrou a viabilidade e a importância de trabalhar desde a educação infantil os valores da cultura afro-brasileira para um processo de aprendizagem que possibilite à criança negra reconhecer-se integrada à sociedade. Mas há criticas no que se refere à apresentação de conteúdos (religiões africanas). Porém o ensino da história e cultura afro-brasileira e africana é importante para garantir uma ressignificação e valorização cultural das matrizes africanas que formam a diversidade cultural brasileira.

Na sequência da entrevista, perguntei a mestra em Psicologia Social sobre as estratégias que ela utilizou para concluir o mestrado. A entrevistada relata que pode contar com ajuda dos pais.

Nesse sentido, a estrutura socioeconômica que a minha família desenvolveu me ajudou e não me obrigou a ter que escolher o caminho de prestar um concurso, e ter um rendimento certo, fixo, para fazer o que precisava naquele momento. Mas, vivi muita incerteza também econômica, financeira, muita oscilação, muita conta vermelha no banco, etc.(Mestra em Psicologia Social).

Se por um lado a entrevistada teve apoio da família para chegar à pós-graduação, por outro, dentro da própria família encontrou obstáculos. 


\title{
V.13, n.1: Ano: 2017
}

Foi difícil porque realmente meu pai não via que me ajudar com o mestrado era uma coisa que fazia sentido para ele, na mentalidade dele e minha mãe tinha muitas questões difíceis, do tipo: "Vocês querem estudar demais. Vocês querem seguir o caminho do seu pai. Vocês me negam e negam as suas origens de pessoas da sua família que não estudaram, e são alguém. Por que vocês não vão buscar alguma coisa na vida, uma profissão em vez de ficar estudando, enchendo o quarto de diploma?" (Mestra em Psicologia Social).

\begin{abstract}
Da minha parte em particular, eu tinha tanta inquietação de entender o que era isso que acontecia com a questão racial negra no Brasil, e eu vi que era o mestrado que ia me ajudar com isso, e que eu queria trabalhar com isso que à medida que eu ia estudando e fazendo pesquisa para o mestrado e trazendo coisas para dentro da minha casa, da casa dos meus pais, sobre essas questões, assuntos que antes eram tabus, que não eram falados, passaram a ser conversados. Mudanças sociais que iam acontecendo, e aí entra o fato que eu entrei no mestrado em 2004, e a Lei 10.639 foi aprovada em 2003, então eu começando a pesquisa já existiam as diretrizes curriculares da Lei 10.639, essas discussões passaram a ser tornar públicas, bem como as políticas de ação afirmativa, passar em noticiários na TV, etc., aí eles começaram a entender o que eu estava fazendo e por que eu queria fazer o mestrado, que sentido isso tinha (Mestra em Psicologia Social).
\end{abstract}

Se, de um lado, a entrevistada tinha suas expectativas, de outro, a família e a sociedade também têm seus projetos. A dificuldade do jovem é integrar essas dimensões, uma vez que sua subjetividade se constrói e é construída no conjunto das relações sociais e de acordo com seu modo de assimilar e de responder às solicitações objetivas do cotidiano e da história. A desigualdade social e as contínuas transformações no mercado de trabalho repercutem na vida e na formação do jovem. Essa realidade provoca o poder público, a sociedade e a família a discutirem a realidade do emprego, da capacitação profissional e da necessidade de políticas públicas (SILVA; SOUZA NETO, 2012).

Perguntei também à entrevistada, se as instituições em que ela estudou discutiam sobre a questão do negro na sociedade brasileira. Neste contexto a mestra em Psicologia Social assinala que era sempre ela, que trazia a temática para a discussão nas instituições em estudou.

Eu trazia essa abordagem, eu trazia esse olhar, desde a graduação, no trabalho de conclusão de curso, na especialização [...] No mestrado eu fiz um esforço pessoal de trazer os autores de perspectiva africana que eu achava importantes para a minha pesquisa (Mestra em Psicologia Social).

Nota-se pelo relato que a entrevistada enfrentou alguns obstáculos em sua trajetória acadêmica, isto é, devido ao seu tema. Para os negros que conseguem ultrapassar as barreiras, e ingressarem na pós-graduação, se deparam com outro obstáculo. Para os que entram, não há 


\section{V.13, n.1: Ano: 2017.}

orientadores suficientes que conheçam os temas, o que impõem dificuldades ao projeto de pesquisa e a trajetória do aluno. Muitas vezes, não há grupos de estudos ou disciplinas que dariam sustentação ao projeto. Nota-se que o problema é grave, mais grave ainda é que nada disso tem sido questionado pela sociedade acadêmica (CUNHA JÚNIOR, 2003).

Por fim perguntei a entrevistada sobre o que é ser uma pesquisadora, e uma "pesquisadora negra" na sociedade brasileira.

Ser uma pesquisadora em minha opinião é buscar referenciais, para desenvolver a sua pesquisa, não significa apenas referenciais teóricos "academicistas". No meu modo de ver, implica em fazer um exercício de olhar a sociedade na qual você está inserido e verificar que referenciais ao redor podem pautar uma reflexão a respeito do tema pesquisado. Ser uma pesquisadora negra, eu acho que implica, demanda que as formas de ser e estar no mundo das civilizações negras seja trazido para a pesquisa, porque senão, a meu ver, seremos apenas pesquisadores de pertença étnico-racial negra, ou de cor negra, fazendo pesquisa dentro do mundo branco, dentro do mundo do "pensamento academicista", racista e egocêntrico. [...] Eu não estou sozinha, não sou eu indivíduo trilhando uma carreira e logrando êxito profissional única e exclusivamente por essa via. Sou eu e toda minha ancestralidade, e todas as pessoas da minha família que me ajudam, me ajudaram, e estão comigo (mestra em Psicologia Social).

Diante do exposto, recorremos às reflexões de Santos (2011):

Pensamos que, a partir dos perfis e trajetórias político-acadêmicas desses intelectuais, especialmente a partir das suas maneiras de sentir, pensar e agir no que diz respeito à questão racial brasileira, bem como de suas condutas acadêmico-intelectuais, é plausível afirmar que está surgindo no Brasil uma nova categoria de intelectuais: os (as) negros (as) intelectuais. Neste sentido, negros (as) intelectuais são, em realidade, os (as) acadêmicos (as) com marcadores de ascendência negra (como, por exemplo, pele escura) que sofreram ou sofrem influência direta ou indireta dos movimentos sociais negros, incorporando desses o preceito de não se resignar ao racismo, não aceitando com passividade a discriminação e o preconceito raciais e, consequentemente, as desigualdades raciais. Preceito esse que, associado e em interação com o conhecimento acadêmico-científico adquirido dos programas de pósgraduação das universidades brasileiras e/ou estrangeiras, produz nesses (as) intelectuais um ethos acadêmico ativo que orienta as suas pesquisas, estudos, ações, assim como as suas atividades profissionais de professores (as) universitários (as). Tal conduta acadêmica leva-os (as) a pesquisar as relações raciais brasileiras, o racismo, o preconceito, a discriminação, as desigualdades raciais e suas consequências virulentas para a população negra, a partir de um ponto de vista que recusa a colonização intelectual eurocêntrica (p.121-122).

Santos (2011, p.122) assinala ainda que nada impede que os intelectuais negros, homens e mulheres "aqueles(as) intelectuais com marcadores de ascendência negra que não militam nem foram militantes de movimentos negros ou que ainda não sofreram influência desses 
REVISTAELETRONICA

HIy

iरEF

GRADUACAO/POS.GRADUACAO EM EDUCACAO

UFG/REJ

V.13, n.1: Ano: 2017.

movimentos, quer direta ou indireta", também possam incorporar "uma ética da convicção antirracismo, associando esta a um conhecimento acadêmico-científico que adquiriram em suas formações acadêmicas”. O que é ser um pesquisador/a negro/a no Brasil? Qual o perfil dos pesquisadores/as negros/as? Estas são questões que ficam como sugestão para futuras pesquisas sobre o tema das relações étnico-raciais.

\section{CONSIDERAÇÕES FINAIS}

O processo da entrevista proporcionou uma experiência intensa e importante no que se refere, aos afetos, a relevância do tema, e pela marcação de um posicionamento do pesquisador e da pesquisada em relação ao processo de uma pesquisa. Corroborando com nossas reflexões, de que não é possível um completo distanciamento entre o sujeito e o objeto, bem como entre as análises teóricas e as posições políticas dos autores, porque os autores partem de algum lugar social-cultural, territorial, temporal.

No que se refere à categoria pesquisador, em particular a pesquisadores/as negros/as, apreendemos que esta discussão perpassa as questões do fenótipo do pesquisador, vai além, carrega um comprometimento ético/político, um ativismo acadêmico como ferramenta para a luta de transformação antirracista.

Notamos que a entrevistada vem de um sistema educacional onde as disciplinas de base dos temas pretendidos pelos estudantes negros pouco existe. Deste modo a entrevistada encontrou dificuldades para o desenvolvimento de sua pesquisa, porque os professores não conheciam o tema das relações raciais com profundidade.

Verificou-se também que a entrevistada trabalhou durante a sua formação educacional no ensino superior (graduação e pós-graduação). Entende-se que muitas vezes, o número de bolsas de estudos é incompatível com as necessidades dos pesquisadores. Observamos também, que desde a infância a entrevistada teve convívio com narrativas sobre questões relacionadas ao racismo e às desigualdades sociais no ambiente doméstico e fora dele. Mas teve o apoio da família, entendemos que a família sempre influenciou e continua a influenciar as escolhas e decisões do sujeito criticamente. Ao longo dos relatos verificamos as nuanças dessa influência. Entretanto, nenhuma instituição, nem mesmo a família, tem poder absoluto sobre os seus membros que conservam sua autodeterminação de fazer opções e traçar caminhos.

Apesar de não ter sido beneficiaria de políticas de ação afirmativa, a entrevistada defende a implementação de ações afirmativas no ensino superior. Entendemos que as políticas 
REVISTA ELETRONICA

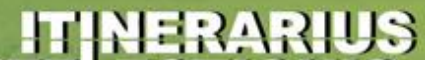

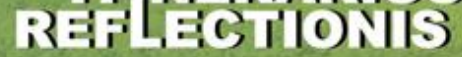

GRADUACAO/POS.GRADUACAO EM EDUCACAO

UFG/REJ

V.13, n.1: Ano: 2017.

de ação afirmativa como uma intervenção em "tempo delimitado", do Estado ou do setor privado, visando ao aumento acelerado da presença de membros de minorias étnico-raciais (grupos sociais sub-representados), em esferas da vida social, como por exemplo: educação, política, empregos, com vistas à promoção da igualdade racial com objetivo de corrigir os efeitos presentes da discriminação praticada no passado, concretizando o ideal de efetiva igualdade de acesso a bens fundamentais e direitos de cidadania plena.

Assim, por um lado, notamos as mudanças introduzidas nas condições de vida da população negra no Brasil verificado nos últimos anos, que são resultado do efeito combinado de iniciativas governamentais que sustentam a política de promoção da igualdade racial e movimentos sociais (Movimento Negro). Por outro, é de fundamental importância à prática de ações no cotidiano do governo e da sociedade brasileira, afim de que possam aperfeiçoar a política de promoção da igualdade racial.

Apreendemos que a entrevistada superou barreiras, criou oportunidades para combater os estereótipos, o racismo, e as desigualdades sociais. Isto é, criou aberturas a partir de sua rede de apoios para permanecer no sistema educacional. As recentes mobilizações dos movimentos sociais (Movimento Negro) na busca por uma igualdade racial reabriu o debate público sobre desigualdade étnico-racial no país. Mas ainda é necessário avançarmos na discussão sobre a formação educacional da população negra. Entendemos que as desigualdades sociais que vigoram na sociedade contemporânea no Brasil, têm fortes raízes históricas e esta realidade não será alterada significativamente sem a aplicação de políticas públicas. Não podemos perder nossa capacidade de pensar criticamente e de querer lutar por uma ordem social sem desigualdades. A entrevista realizada com a mestre em Psicologia Social nos provoca a alargar nossos horizontes para além do campo da Psicologia e das humanidades.

\section{REFERÊNCIAS}

ACEVEDO, C. R.; NOHARA, J.; RAMUSKI, C.L. Relações raciais na mídia: um estudo no contexto brasileiro. Rev. psicol. polít., São Paulo, v. 10, n. 19, p. 57-73, jan. 2010.

ARTES, A. Desigualdade de cor/raça e sexo entre pessoas que frequentam e titulados na pós-graduação brasileira 2000 e 2010. Relatório de Pesquisa do Projeto Equidade na PósGraduação, Fundação Carlos Chagas, São Paulo, SP, 2015. 
REVISTAELETRONICA

HIy

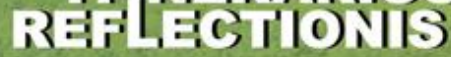

GRADUACSAO/POS-GRADUACAO EMIEDUCACAO UFG/RE:

- ISSN $1807-93842$

V.13, n.1: Ano: 2017.

ARTES, A.; UNBEHAUM, S.; SILVÉRIO, V, (orgs.). Ações Afirmativas no Brasil: reflexões e desafios para a pós-graduação. São Paulo: Cortez: Fundação Carlos Chagas, 2016.v.2.

ARTES, A.; UNBEHAUM, S.; SILVÉRIO, V., (orgs.). Ações Afirmativas no Brasil: experiências bem-sucedidas de acesso na pós-graduação. São Paulo: Cortez: Fundação Carlos Chagas, 2016.v 1.

BARDIN, L. Análise de conteúdo. Tradução de Luís Antero Reto e Augusto Pinheiro. Lisboa: Capa de Edições 70, 2011.

BARROS, M. L. Narração de mitologias afro-brasileiras na educação infantil: possibilidades de atuação para uma aprendizagem democrática. Rev. SPAGESP, Ribeirão Preto, v. 13, n. $1,2012$.

BELTRÃO, K. I.; TEIXEIRA, M. de P. O vermelho e o negro: raça e gênero na universidade brasileira - uma análise da seletividade das carreiras a partir dos censos demográficos de 1960 a 2000 [Texto para discussão]. Rio de Janeiro: Ipea, 2004.

BOCK, A. M. B. A adolescência como construção social: estudo sobre livros destinados a pais e educadores. Psicol. Esc. Educ. (Impr.), Campinas, v. 11, n. 1, p. 63-76, Jun. 2007.

BOURDIEU, P. A Escola conservadora: as desigualdades frente à escola e à cultura. In: NOGUEIRA, M. A.; CATANI, A. (Orgs.). Escritos de educação. Petrópolis, Vozes, 1998.

BRASIL. Lei 10.639, de 09 de janeiro de 2003. Brasília, DF, 09 de janeiro de 2003. Disponível em: < http://www.planalto.gov.br/ccivil_03/leis/2003/L10.639.htm>. Acesso em: 28 JAN.2017.

Lei 11.645, de 10 de março de 2008. Brasília, DF, 10 de março de 2008. Disponível em: < http://www.planalto.gov.br/ccivil_03/_ato2007-2010/2008/lei/111645.htm>. Acesso em: 28 jan. 2017.

CGEE. Mestres e doutores 2015: Estudos da demografia da base técnico-científica brasileira.

- Brasília, DF: Centro de Gestão e Estudos Estratégicos, 2016.

CUNHA JÚNIOR, H. A formação de pesquisadores negros no Brasil. Plano 500 de Política Científica Nacional (uma proposta de um pesquisador militante). Revista Espaço Acadêmico, Maringá, vol. 3, n. 27, ago. 2003. 
REVISTAELETRONICA

HIy

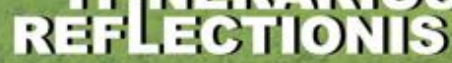

GRADUACAO/POS.GRADUACAO EM EDUCACAO

UFG/RED

V.13, n.1: Ano: 2017.

CURY, C. R. J. Ensino religioso na escola pública: o retorno de uma polêmica recorrente.

Revista Brasileira de Educação, Rio de Janeiro, RJ, Set /Out /Nov /Dez 2004, n 27.

ESSED, P. Understanding everyday racism: interdisciplinary theory. Londres: Sage, 1991.

GUIMARÃES, A.S.A. Racismo e anti-racismo no Brasil. São Paulo: Editora 34, 2005.

Classes, raças e democracia. São Paulo: Editora 34, 2002.

INSTITUTO DE PESQUISA ECONÔMICA APLICADA. Situação social da população negra por estado. Brasília: IPEA, 2014.

MARTINS, E.; GERALDO, A. G.. A Influência da Família no Processo de Escolarização e Superação do Preconceito Racial: um estudo com universitários negros. Rev. psicol. polít., São Paulo, v. 13, n. 26, p. 55-73, abr. 2013.

PAIXÃO, Marcelo. (Org.). Relatório anual das desigualdades raciais no Brasil: 2009-2010. Rio de Janeiro, Universidade Estadual do Rio de Janeiro, Rio de Janeiro, 2010.

RIBEIRO, M. S. Diversidade cultural nas políticas públicas: uma análise das Leis 10. 693/03 e 11.645/08. 2011. Mimeografado.

ROSEMBERG, F. Da intimidade aos quiprocós: uma discussão em torno da análise de conteúdo. Cadernos CERU, São Paulo, n.16, p. 69-80, nov. 1981.

.Políticas educacionais e gênero: um balanço dos anos 1990. Cadernos

Pagu, Campinas, n. 16, p. 151-198, 2001.

ROSEMBERG, F.; BAZILLI, C.; SILVA, P. V. B. Racismo em livros didáticos brasileiros e seu combate: uma revisão da literatura. Educação e Pesquisa, São Paulo, v. 29, n. 1, p. 125146, jan/jun 2003.

ROSEMBERG, F.; MADSEN, N. Educação formal, mulheres e gênero no Brasil contemporâneo. In: BARSTED, Leila Linhares; PITANGUY, Jacqueline. (Org.). O Progresso das Mulheres no Brasil 2003-2010. Rio de Janeiro/Brasília: Cepia/Unesco, v.1 p.390-433, 2011.

ROSSLER, J. H. Trabalho, educação e psicologia na sociedade contemporânea: c formação do indivíduo no contexto da atual reestruturação produtiva. In: MEIRA, M. E. M. A. e FACCI, 
V.13, n.1: Ano: 2017.

M.G.D. (Org.). Psicologia histórico-cultural, contribuições para o encontro entre a subjetividade e a educação. São Paulo: Casa do Psicólogo, 2007.

SANTOS, A. O.; SCHUCMAN, L.V.; MARTINS, H.V. Breve histórico do pensamento psicológico brasileiro sobre relações étnico-raciais. Psicol. cienc. prof., Brasília , v. 32, n. spe, p. $166-175,2012$.

SANTOS, S. A. A metamorfose de militantes negros em negros intelectuais. Mosaico, Rio de Janeiro, v. 3, n. 5, jun. 2011.

SAWAIA, B. B. Psicologia e desigualdade social: uma reflexão sobre liberdade e transformação social. Psicologia \& Sociedade; 21 (3): 364-372, 2009.

SILVA, M. A.B.; SOUZA NETO, J. C. Inserção no mundo do trabalho: percepção do adolescente do ensino médio. In: CONGRESSO INTERNACIONAL DE PEDAGOGIA SOCIAL, 4., 2012, São Paulo. Proceedings online... Associação Brasileira de Educadores Sociais. Acesso em: 28 jan. 2017.

TEIXEIRA, M.P. Negros na universidade: identidade e trajetórias de ascensão social no Rio de Janeiro. Rio de Janeiro: Pallas, 2003.

TELLES, E. Racismo à brasileira: uma nova perspectiva sociológica. Rio de Janeiro: RelumeDumará, 2003.

THOMPSON, J. B. Ideologia e cultura moderna: teoria social crítica na era dos meios de comunicação de massa. Petrópolis, RJ: Vozes, 2011. 